J. Product. \& Dev., 19(2):155 - 180 (2014)

\title{
IMPACT OF FOLIAR SPRAY WITH POTASSIUM ON THE PRODUCTIVITY, QUALITY AND STORABILITY OF SOME SWEET PEPPER HYBRIDS GROWN IN PLASTIC HOUSE
}

\author{
H. E. M. Ismail ${ }^{1}$ and Omaima, O. Mohamed ${ }^{2}$ \\ 1. Hort. Department, Faculty of Agriculture, Zagazig University, Egypt \\ 2. Post Harvest and Handling of Vegetables Crops Department, Hort. Res. \\ Inst., ARC, Egypt.
}

\begin{abstract}
Two experiments were carried out during winter seasons of 2011/2012 and 2012/2013 in a Private Farm at Al-Salhia El-Jadida, Region, Sharkia Governorate, and Laboratory of Handling of Vegetable Crops Department, Horticulture Research Institute, Agriculture Research Center, Giza, Egypt, to study the effect of foliar spray with potassium citrate at three levels (Zero, $2 \mathrm{~g} / \boldsymbol{\ell}$ and $4 \mathrm{~g} / \boldsymbol{\ell}$ ) on yield and its components, fruit quality and storability during cold storage of some sweet pepper hybrids (Drasena and Shanghai) grown under plastic house conditions.

There were no significant differences between the two hybrids with respect to yield and its components. Foliar spray with potassium citrate at $4 \mathrm{~g} / \boldsymbol{\ell}$ led to a significant increase in number of fruits per plant, yield per plant and total yield per $100 \mathrm{~m}^{2}$ in both seasons and improving fruit quality expressed as firmness, color, TSS and vitamin $\mathrm{C}$ during storage at $10{ }^{\circ} \mathrm{C}$ and $90 \% \mathrm{RH}$ for 21 days. Spraying sweet pepper Shanghai hybrid with potassium citrate at $4 \mathrm{~g} / \boldsymbol{\ell}$ recorded the best values of yield and its components, and improved storability during cold storage for 14 days by reducing weight loss percentage and gave fruits with good color.
\end{abstract}

Conclusively, from the previous results of this investigation, it could be concluded that spraying sweet pepper Shanghai hybrid with potassium citrate at $4 \mathrm{~g} / \ell$ was sufficient to produce the highest yield and its components, and improved quality and storability of fruits.

Key words: Sweet pepper, hybrids, potassium, yield, cold storage, foliar spray

\section{INTRODUCTION}

Yellow and red pepper (Capsicum annum L.) are one of the rich sources of bioactive compounds, especially, carotenoids and vitamin C (Howard et al.,2000; Antoniali et al.,2007; Sakaldas and Kaynas 2010) and 
contains moderate to high level of phenolics and flavonoids contents (Hasler, 1998 and Howard et al.,2000). The main factors affecting postharvest quality of bell pepper are shriveling, decay development and chilling injury, at the temperature below 7 to $10^{\circ} \mathrm{C}$ (Vicente et al., 2005; Sakaldas and Kaynas 2010).

Potassium is the most prominent inorganic plant solute and is the only mineral nutrient that is not a constituent of organic structures. Among the many plant mineral nutrients, potassium stands out as a cation having the strongest influence on quality attributes that determine fruit marketability, consumer preference and the concentration of critically important human health-associated phyto-nutrients (Lester et al., 2010). Its function is mainly in osmo-regulation process, the maintenance of electrochemical equilibria in cells and its compartments and the regulation of enzyme activities (Hsiao and Läuchli, 1986). Also potassium has a crucial role in the energy status of the plant, translocation and storage of assimilates and maintenance of tissue water relation (Imas and Bansal 1999). Potassium plays a key role of crop quality, it improves size of fruit and stimulates root growth. It is necessary for the translocation of sugars and formation of carbohydrates. Potassium also provides resistance against pest and diseases and drought as well as frost stresses (Marschner1995a).

Nowadays, in Egypt, potassium fertilizers became a highly expensive ones of input factors in production processes (ton $~ 1000 \$$ ), so many farmers minimizing the used amount to the minimum dose. In addition to use any other newly and cheapest potassium sources through foliar application as a stimulative dose to overcome such problem and to maximize their net return to cover the additional cost of this fertilizer source.

Increasing productivity as well as fruit quality and chemical composition due to increasing potassium fertilization levels have been reported by many workers on different crops, foliar application of potassium chloride at $2 \%$ significantly improved pepper growth parameters and yield compared to control plants (El-Tohamy et al., 2006). Also, pepper yield and productivity can be improved by foliar spray with potassium (Nassar et al., 2001). El-Bassiony et al., (2010) found that the favorable effects of the potassium on the total yield and fruit parameters were obtained when sweet pepper plants fertilized with $200 \mathrm{~kg} / \mathrm{fed}$. potassium sulfate plus foliar application of potassium humate at 4 $\mathrm{gm} / \mathrm{L}$. Soil and/or foliar K-humate applications might successfully be used to obtain higher fruit yield and can significantly enhance pepper fruit quality as demonstrated by Arancon et al. (2006). Darwesh and Atress (2011) found that spraying snow pea plants with potassium at $2 \mathrm{gm} / \mathrm{L}$ led to reducing weight loss and total sugars loss during storage, and maintained snow pea pods with good appearance for 28 days.

Regarding sweet pepper hybrids, among three capsicum cultivars, Colombo, Galaxy and Gedcon grown under plastic house, cultivar Colombo 
produced highest fruit yield $(4.17 \mathrm{~kg} /$ plant $)$ with more fruit length $(11.98 \mathrm{~cm})$, increased fruit weight $(230.0 \mathrm{~g})$, diameter of fruit $(7.75 \mathrm{~cm})$, dry matter content (4.59\%) and high TSS (4.27\%) according to studies by Rahman and EI -Sheikh (1994). Munij and Almedia (1998) observed that, among six capsicum cultivars evaluated for commercial yields, number of fruits per plant, fruit weight and size, the most productive cultivars were Ruby King, Early Calwonder and Ikeda (15.8-19.5, 15.5-19.5 and 16.6-18.4 tonnes per ha, respectively). The cultivar Nara gave lowest yield (12.0-12.7 t/ha).

Therefore, the main objective of this study was to investigate the effect foliar spraying of potassium on yield and its components, fruit quality and storability of some sweet pepper hybrids.

\section{MATERIALS AND METHODS}

\section{Plastic house experiment:}

This experiment was carried out under plastic house conditions during winter seasons of 2011/2012 and 2012/2013 in Private Farm at AlSalhia Al-Jadida Region, Sharkia Governorate to study the effect of foliar spray with potassium citrate on the productivity of some sweet pepper hybrids. This experiment included 6 treatments, which were the combination between two hybrids (Drasena and Shanghai) and foliar spray with three levels of potassium citrate (zero, $2 \mathrm{~g} / \ell$ and $4 \mathrm{~g} / \boldsymbol{\ell}$ ). The treatments were arranged in a split plot design with three replicates, sweet pepper hybrids were randomly assigned in the main plots, while foliar spraying with potassium citrate treatments were randomly distributed in the main sub-plots. The area of each plot was $10.8 \mathrm{~m}^{2}$ with 50 plants $(10 \mathrm{~m} \mathrm{X} 1.8 \mathrm{~m})$. Treatments of potassium were sprayed three times, i.e., 40,55and 70 days from transplanting. Each plot received $2 \ell$ solution for each level and using spreading agent (super film $1 \mathrm{ml} / \mathfrak{\ell}$ ), the untreated plants were sprayed with tap water and spreading agent. The source of potassium was potassium citrate compound $\left(\mathrm{K}_{3} \mathrm{C}_{6} \mathrm{H}_{5} \mathrm{O}_{7} \cdot \mathrm{H}_{2} \mathrm{O}\right)$ it was obtained from El-Gomhouria Co. for trading medicines, chemicals and medical appliances, Sharkia Governorate, Zagazig, Egypt. This experimental soil was sandy in texture. Seeds of sweet pepper (Capsicum annuum L.) Drasena (red pepper) and Shanghai (yellow pepper) F1 hybrids were obtained from Seminis Grow Forward Co. and Introduced by Sand Valley Co. Nasr City, Cairo, Egypt. Seeds were sown at the nursery on $20^{\text {th }}$ and $10^{\text {th }}$ of August in 2011 and 2012 season, respectively, and the seedlings were transplanted on $26^{\text {th }}$ and $29^{\text {th }}$ of September in 2011 and 2012 season. The plastic house was $60 \mathrm{~m}$ long and $9 \mathrm{~m}$ wide $\left(540 \mathrm{~m}^{2}\right)$ and divided into five ridges each $(1.8 \mathrm{~m}$ wide and $60 \mathrm{~m}$ long) seedlings were transplanted on the two sides of each ridge and $40 \mathrm{~cm}$ apart. 
All agricultural practices i.e., drip irrigation, soil and feritigation fertilization and weed and pest control were followed as recommended of plastic house cultivations. The physical and chemical properties analyses of the soil under study were presented as average in both seasons in Table 1 .

\section{Data recorded:}

Yield and its components: At harvesting time second week of December (72 days from transplanting), pepper fruits were picked, counted and weighed weekly through the harvesting period till the end of season (first week of April) at both seasons and the following data were recorded: fruit number /plant, average fruit weight $(\mathrm{g})$, fruit length $(\mathrm{cm})$, plant yield $(\mathrm{kg})$ and total yield/ $100 \mathrm{~m}^{2}(\mathrm{~kg})$.

\section{Storage experiment:}

This experiment was conducted to study the effect of potassium rates on keeping quality of yellow and red pepper fruits during cold storage period. In this experiment, yellow and red pepper fruits which obtained from the field experiment harvested at the full color mature stage on $16^{\text {th }}$ January, transported to the laboratory of Handling of Vegetable Crops Department, Horticulture Research Institute, Agriculture Research Center, Giza, Egypt, healthy fruits and free from each blemishes were selected for storage experiment.

Twelve experimental units (EU) were prepared for each treatment. Each $\mathrm{Eu}$ consisted of three fruits which packed in plastic perforated bags and placed in carton box $(20 \times 15 \times 10 \mathrm{~cm})$. All treatments were stored at at $10^{\circ} \mathrm{C}$ and $90-95 \%$ relative humidity for 21 days. A complete randomized design was adopted. Three replicates (EUs) from each treatment were taken at random and examined at seven days intervals (at days 7, 14, 21) for the following properties:

1-Weight loss percentage: It was estimated according to the following equation:

Weight loss $\%=[$ (Initial weight of fruits - Weight of fruits at sampling dates $)$

(Initial weight)] x 100

2- Color measurement: It was measured using a color meter (Minolta, model CR 200). Color changes were quantified in the $L^{*}, A^{*}$ and $B^{*} . L^{*}$ measures color lightness ( $\mathrm{L}^{*}$ values are always positive where higher values are lighter color), $\mathrm{A}^{*}$ measures color chromaticity that indicates color direction (where positive values of $\mathrm{A}^{*}$ point to the red direction and negative values of $\mathrm{A}^{*}$ point to the green direction) and $\mathrm{B}^{*}$ in the second chromaticity measure that indicates color direction (where positive values of $\mathrm{B}^{*}$ point to the yellow direction and negative values of $\mathrm{B}^{*}$ point to the blue direction), chroma represents color saturation which varies from light green (low value) to dark green color (high value). 
Table 1. The soil physical and chemical properties of the experimental site during2011/2012 and2012/2013 seasons.

\begin{tabular}{|c|c|c|}
\hline Properties & $2011 / 2012$ & $2012 / 2013$ \\
\hline \multicolumn{3}{|l|}{ Physical Properties (\%): } \\
\hline Sand & 95.2 & 95.6 \\
\hline Silt & 2.5 & 2.0 \\
\hline Clay & 2.3 & 2.4 \\
\hline Texture & Sandy & Sandy \\
\hline \multicolumn{3}{|l|}{ Chemical properties: } \\
\hline Organic matter $(\%)$ & 0.05 & 0.07 \\
\hline $\mathrm{pH}$ & 7.6 & 7.4 \\
\hline Available N & 7.3 & 6.8 \\
\hline Available P & 6.8 & 7.1 \\
\hline Available K $\quad$ (ppm) & 58 & 65 \\
\hline Calcium carbonate $(\%)$ & 0.22 & 0.29 \\
\hline
\end{tabular}

3- Fruit firmness: It was measured by a hand pressure tester (Italian model) expressed in $\mathrm{kg} / \mathrm{cm}^{2}$ (Abbott, 1999).

4- Total soluble solids (TSS): It was determined by using a hand Refractometer according to the methods mentioned in A.O.A.C. (1990).

5- Vitamin $C$ content $(\mathbf{m g} / \mathbf{1 0 0 g}$ fresh weight): It was determined by titration method using 2, 6 dichloro-phenol-indo phenol as described in A.O.A.C. (1990).

Statistical analysis:

All data obtained were subjected to the proper statistical analysis using the MSTAT statistical software and the treatments means were compared by using the LSD at 0.05 level of probability as described by Snedecor and Cochran (1980).

\section{RESULTS AND DISCUSSION}

Plastic house experiment:

\section{Yield and its components:}

Data recorded in Table 2 show clearly the effect of foliar spray with potassium citrate on yield and its components of some sweet pepper hybrids grown under plastic houses. Concerning the effect of hybrids, it is obvious from the data that, the two pepper hybrids (Drasena and Shanghai) did not reflected significant effect on yield and its components.

As for the effect of foliar spray with potassium citrate on yield and its 
components, the results showed that spraying sweet pepper plants with potassium citrate at $4 \mathrm{~g} / \ell$ increased significantly number of fruits per plant, average fruit weight, yield per plant and yield per $100 \mathrm{~m}^{2}$. The improving effect of potassium fertilization on yield and its components may be attributed to that potassium is the most abundant cation present in the phloem sap (almost $80 \%$ of the total cations) as a consequence of sugar charging and transport mechanisms/processes through the phloem into sink organs. (Cakmak, 2005). It is well known that potassium plays a key role in carbohydrate metabolism and photosynthesis (Marschner, 1995b) and, as a consequence, an optimum potassium supply determines better sugar content into sink organs. These results are true in both seasons of study. The present results are in accordance with Nassar et al., 2001, Arancon et al. 2006, ElTohamy et al., 2006 and El-Bassiony et al., 2010 on sweet pepper.

The interaction between sweet pepper hybrids and potassium reveled that spraying each Drasena and Shanghai hybrids with potassium citrate at $4 \mathrm{~g} / l$ in both seasons recorded the highest values of number of fruits per plant, fruit weight, fruit length, yield per plant and total yield per $100 \mathrm{~m}^{2}$ except fruit weight and fruit length in the first season with out any significant differences between them. On the other hand the untreated plants recoded the lowest values of all studied characters.

\section{Storage experiment: \\ Weight loss percentage:}

The results in Table 3 demonstrate that there were significant differences between the two hybrids in weight loss percentage, where hybrid Drasena gave the maximum weight loss percentage (2.47 and 2.43\%) hybrid Shanghai recorded the minimum weight loss percentage $(1.99$ and $1.98 \%)$ in the $1^{\text {st }}$ and $2^{\text {nd }}$ seasons , respectively, these results are true in both seasons.

Concerning the effect of spraying with potassium, the results show that spraying pepper plants with potassium at $4 \mathrm{~g} / \ell$ significantly reduced the weight loss percentage in the stored sweet pepper fruits as compared to other treatments. Similar results were obtained on carrot by Shibairo et al., (1998) who stated that increasing K concentration in the nutrient medium decreased post harvest moisture loss by increasing weight and by maintaining tissue integrity. As for storage period, it is clear that there was a considerable increase in weight loss percentage of stored sweet pepper fruits at the storage period prolonged, where the maximum loss was occurred at the end of the storage period (21days). These results might be due to the loss in moisture through transpiration. Similar results were obtained by Hassan (2002) who found that, weight loss is cumulative and generally linear with time in storage, the increase in limpness and shriveling and subsequently the 
Table (3): Effect of foliar spray with potassium citrate and cold storage periods on weight loss \% of some sweet pepper hybrids grown in plastic houses during 2011/2012 and 2012/2013 seasons.

\begin{tabular}{|c|c|c|c|c|c|c|c|c|c|c|c|}
\hline \multirow{4}{*}{ 茫 } & \multirow{4}{*}{ 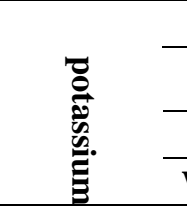 } & \multicolumn{6}{|c|}{ 2011/2012 Season } & \multicolumn{4}{|c|}{ 2012/2013 Season } \\
\hline & & \multicolumn{10}{|c|}{ Cold storage period (days) } \\
\hline & & $\mathbf{0}$ & 7 & 14 & 21 & Mean & 0 & 7 & 14 & 21 & Mean \\
\hline & & \multicolumn{10}{|c|}{ Weight loss\% } \\
\hline \multirow{5}{*}{ 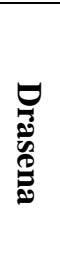 } & Without & - & 1.82 & 2.71 & 3.50 & 2.68 & - & 1.82 & 2.62 & 3.46 & 2.63 \\
\hline & $2 g / \ell$ & - & 1.62 & 2.64 & 3.25 & 2.51 & - & 1.63 & 2.55 & 3.06 & 2.41 \\
\hline & $4 g / \ell$ & - & 1.64 & 2.50 & 2.58 & 2.24 & - & 1.67 & 2.44 & 2.64 & 2.25 \\
\hline & Mean & - & 1.69 & 2.62 & 3.11 & 2.47 & - & 1.71 & 2.54 & 3.05 & 2.43 \\
\hline & Without & - & 1.77 & 2.40 & 2.66 & 2.28 & - & 1.76 & 2.44 & 2.61 & 2.27 \\
\hline \multirow{3}{*}{ 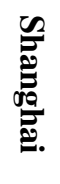 } & $2 g / \ell$ & - & 1.29 & 2.33 & 2.57 & 2.06 & - & 1.26 & 2.29 & 2.56 & 2.03 \\
\hline & $4 \mathrm{~g} / \ell$ & - & 0.82 & 1.70 & 2.36 & 1.63 & - & 0.83 & 1.63 & 2.44 & 1.63 \\
\hline & Mean & - & 1.29 & 2.14 & 2.53 & 1.99 & - & 1.28 & 2.12 & 2.54 & 1.98 \\
\hline & Means & - & 1.49 & 2.38 & 2.82 & 2.23 & - & 1.49 & 2.33 & 2.80 & 2.21 \\
\hline & $\begin{array}{l}\text { Without } \\
\text { Potassium }\end{array}$ & - & 1.80 & 2.56 & 3.08 & 2.48 & - & 1.79 & 2.53 & 3.04 & 2.45 \\
\hline \multirow{2}{*}{\multicolumn{2}{|c|}{ 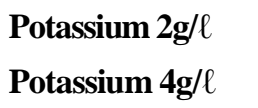 }} & - & 1.46 & 2.49 & 2.91 & 2.28 & - & 1.44 & 2.42 & 2.81 & 2.22 \\
\hline & & - & 1.23 & 2.10 & 2.47 & 1.93 & - & 1.25 & 2.04 & 2.54 & 1.94 \\
\hline \multicolumn{2}{|c|}{ L.S.D at 5\% } & \multicolumn{2}{|c|}{$1^{\text {st }}$ Season } & \multicolumn{2}{|c|}{$2^{\text {nd }}$ Season } & & & \multicolumn{2}{|c|}{$1^{\text {st }}$ Season } & \multicolumn{2}{|c|}{$2^{\text {nd }}$ Season } \\
\hline \multirow{2}{*}{\multicolumn{2}{|c|}{$\begin{array}{l}\text { Hybrids (C) } \\
\text { Potassium (K) }\end{array}$}} & & 0.45 & 0.3 & & \multicolumn{2}{|c|}{$\mathrm{CXK}$} & & 0.32 & \multicolumn{2}{|c|}{0.22} \\
\hline & & & 0.23 & 0.1 & & \multicolumn{2}{|c|}{$\mathrm{C} \times \mathrm{Sp}$} & & 0.32 & \multicolumn{2}{|c|}{0.16} \\
\hline \multirow{2}{*}{\multicolumn{2}{|c|}{ Storage period $(\mathrm{Sp})$}} & & 0.23 & 0.1 & & \multirow{2}{*}{\multicolumn{2}{|c|}{$\mathrm{K} \times \mathrm{Sp}$}} & & 0.25 & \multirow{2}{*}{\multicolumn{2}{|c|}{0.18}} \\
\hline & & & & & & & & 0.36 & & & \\
\hline
\end{tabular}

Loss of crispness follow weight loss of sugar peas. Regarding the effect of interaction between hybrids and spraying with potassium citrate the results show that spraying Shanghai hybrid plants with potassium citrate at $4 \mathrm{~g} / \mathrm{l}$ detected the lowest significant weight loss as compared to other treatments.

The interaction between hybrids and cold storage period show significant effect in both seasons, the lowest values of weight loss percentage at the end of the cold storage period (21days) were noted by Shanghai hybrid as compared to Drasena hybrid. With respect to the interaction between spraying with potassium and cold storage period the same results show that spraying plants with potassium at $4 \mathrm{~g} / \ell$ recorded the lowest values of weight loss percentage at the end of the cold storage period 2.47 and 2.54 in the $1^{\text {st }}$ and $2^{\text {nd }}$ seasons, respectively, followed by spraying plants with potassium at $2 \mathrm{~g} / \ell$ with non significant differences between them. 
Regarding the effect of the interaction among hybrids, spraying with potassium citrate and cold storage period, it is clear that the lowest values of weight loss percentage at the end of the cold storage period were noted by Shanghai hybrid when sprayed with potassium citrate at $4 \mathrm{~g} / \ell$ which gave 2.36 and 2.44 in the $1^{\text {st }}$ and $2^{\text {nd }}$ seasons, respectively, followed by the interaction treatment among hybrids Shanghai $X$ spraying with potassium citrate at $2 \mathrm{~g} / \ell \mathrm{X}$ cold storage period at 21 days with no significant differences between them. These results are true in both seasons of study.

\section{External fruit color:}

\section{A- Color measurement L (lightness):}

The results for lightness (color L) appear in Table 4 show that there were significant differences between the two hybrids in lightness, where hybrid Shanghai gave the maximum values of color L (51.76 and 51.82) hybrid Drasena recorded the minimum values $(34.45$ and 34.40$)$ in the $1^{\text {st }}$ and $2^{\text {nd }}$ seasons, respectively. As to spraying with potassium citrate the same results show that spraying pepper plants with the two levels of potassium citrate increased significantly fruit lightness without significant differences between them, while the lowest values of color L were recorded by the fruits which obtained from untreated plants.

With respect to storage period it is clear from the data that fruit lightness was significantly increased as the beginning of storage and then decreased with the prolongation of the cold storage period in the two seasons.

Concerning the interaction between hybrids and spraying with potassium citrate the results show that spraying Shanghai hybrid with the two levels of potassium increased significantly fruit lightness without significant differences between them.

The interaction between hybrids and cold storage period show that the highest values of fruit lightness were recorded by Shanghai hybrid at the harvesting time, while the lowest significant fruit lightness was noted by Drasena hybrid at the end of the cold storage period (21days). With regard to the interaction between spraying with potassium and storage period the same results in Table 4 show that spraying pepper hybrids with potassium citrate at $4 \mathrm{~g} / \ell$ recorded the highest significant of fruit lightness at the harvesting time followed by spraying with potassium citrate at $2 \mathrm{~g} / \ell$ at the harvesting time without significant differences between them. On the other hand the lowest significant of fruit lightness were recorded at the end of cold storage period (21days) by the fruits which obtained from untreated plants. Concerning the effect of the interaction among hybrids, spraying with potassium citrate e and storage period the data indicate that the highest values of color $\mathrm{L}$ were obtained from Shanghai hybrid at the harvesting time 
when sprayed with each of the two levels of potassium without significant differences between them, while the lowest significant of fruit color L were recorded by Drasena hybrid at the end of storage period (21days) when untreated with potassium in the two seasons.

\section{$B$-Color measurement B:}

Regarding the effect of hybrids on color B values it is obvious from the data in Table 5 that Shanghai hybrid recorded the maximum values of color B as compared with Drasena hybrid which gave the minimum values in both seasons. Concerning the effect of potassium citrate the results show that spraying pepper hybrids plants with potassium citrate did not reflected significant effect on color B in first season, while untreated plants recorded the highest significant effect in second season.

As for cold storage period, it is clear from the same data that color B in fruits significantly decreased at the beginning of storage ad then increased significantly with the prolongation of the cold storage period in the two seasons. With regard to the interaction between hybrids and potassium citrate the results show that spraying Shanghai hybrid with potassium citrate at $2 \mathrm{~g} / \ell$ increased significantly color $B$ values. On the other side the lowest values of color B were recorded by spraying Drasena hybrid with potassium citrate at $2 \mathrm{~g}$ $/ \ell$. The interaction between hybrids and storage period show that the highest values of color B were recorded by Shanghai hybrid at the end of the cold storage period (21days), while the lowest significant of color B was noted by Drasena hybrid at the harvesting time.

With respect to the interaction between potassium citrate and cold storage period the same results in Table 5 show that spraying pepper hybrids with potassium citrate at the two levels gave the highest significant values color B at the end of the storage period, while the lowest significant values of color B were recorded by spraying with potassium at $2 \mathrm{~g} / \ell$ at the harvesting time. Regarding the effect of the interaction among hybrids, potassium citrate and storage period the data indicate that the highest values of color B were obtained by Shanghai hybrid at the end of storage period (21days) when sprayed with each of the two levels of potassium citrate, while the lowest values of color B were recorded by Drasena hybrid at harvesting time when sprayed with potassium at $2 \mathrm{~g} / \ell$.

\section{C-Color measurement A:}

Concerning the effect of hybrids on values of color $\mathrm{A}$ it is clear from the data in Table 6 that the values of color A become less negative with Shanghai hybrid -4.12 and -4.16 in the $1^{\text {st }}$ and $2^{\text {nd }}$ seasons, respectively, indicating degradation of chlorophyll (green color) as compared with Drasena hybrid which recorded the highest positive values of color A. 
As for the effect of potassium citrate the results show that spraying sweet pepper hybrids with potassium citrate did not reflected significant effect on color A in first season, while spraying with potassium at $4 \mathrm{~g} / \ell$ recorded the highest values in the second season.

Regarding storage period, it is clear from the same data that color A in sweet pepper fruits significantly decreased at the harvesting time and then increased significantly with the prolongation of the cold storage period in both seasons. With respect to the interaction between hybrids and potassium, the results show that spraying Shanghai hybrid with potassium citrate at $4 \mathrm{~g} / \mathrm{\ell}$ recorded the lowest negative values of color $\mathrm{A}$, while the highest positive values were recorded by spraying Drasena hybrid with potassium citrate at $4 \mathrm{~g} / \ell$.

The interaction between hybrids and cold storage period show that the highest positive values of color A were recorded by Drasena hybrid at the end of the storage period (21days). On the other side the lowest negative values were noted by Shanghai hybrid at the end of cold storage period. Concerning the interaction between potassium citrate and cold storage period the results indicate that the untreated plants at the end of storage period gave the highest significant of color A followed by spraying with potassium citrate at $2 \mathrm{~g} / \ell$ at the end of the storage period without significant differences between them, while the lowest significant values were noted by spraying with potassium citrate at $2 \mathrm{~g} / \ell$ at harvesting time in both seasons.

With regard to the interaction among hybrids, potassium and cold storage period the data show that the highest positive values of color A were obtained by Drasena hybrid at the end of cold storage period (21days) when untreated with potassium citrate, while the lowest negative values were recorded by Shanghai hybrid at the end of cold storage period when spraying with potassium citrate at $4 \mathrm{~g} / \ell$ in the two seasons of study.

\section{D- Chroma:}

Regarding the effect of hybrids on chroma values it is clear from the data in Table 7 that the lowest values of chroma were recorded by Drasena hybrid, while the highest values were recorded by Shanghai hybrid.

As for the effect of potassium the results show that spraying sweet pepper plants with the two levels of potassium citrate increased significantly chroma values without significant differences between them, on the other side the lowest values of chroma were recorded by the fruits which obtained from untreated plants. Concerning cold storage period it is clear from the same data that values of chroma in pepper fruits significantly decreased at the beginning of storage and then increased significantly with the prolongation of the storage period. With regard to the interaction between hybrids and potassium citrate the results show that spraying Shanghai 
hybrid with potassium citrate at $4 \mathrm{~g} / \ell$ increased significantly chroma values, while the lowest values were recorded from untreated Drasena hybrid plants. The interaction between hybrids and cold storage period show that the highest values of chroma were recorded by Shanghai hybrid at the end of storage period (21days), while the lowest significant chroma values were noted by Drasena hybrid at the harvesting time.

With respect to the interaction between potassium citrate and storage period the same results show that spraying pepper hybrids with potassium citrate at $4 \mathrm{~g} / \ell$ gave the highest significant values of chroma at the end of the cold storage period, while the lowest significant values were recorded by untreated plants at the harvesting time.

Regarding the effect of interaction among hybrids, potassium citrate and cold storage period the data indicate that the highest values of chroma were obtained by Shanghai hybrid at the end of cold storage period (21days) when sprayed with potassium citrate at the two levels, while the lowest values were recorded by untreated Dracena hybrid plants at the beginning of storage.

\section{Total soluble solids (TSS):}

Concerning the effect of hybrids, it is obvious from the data in Table 8 that, the two pepper hybrids (Drasena and Shanghai) did not reflected significant effect on total soluble solids. Regarding the effect of spraying with potassium citrate the results show that, spraying pepper plants with the two levels of potassium increased significantly TSS\% without significant differences between them. On the other hand, the lowest values of TSS\% were recorded from untreated plants (control). Concerning storage period, it is clear from the results in Table 8 that, pepper fruits TSS\% was decreased as the duration of storage is increased. The results demonstrated that total soluble solids of fruits were significantly increased at the beginning of cold storage and then decreased with the prolongation of the storage period in the two seasons. Similar results were obtained by El-Sheikh et al., (1997) and Ahmed (2013) on sweet pepper, they found that TSS\% of fruits were significantly increased at the beginning of storage and decreased with the prolongation of cold storage period. The increase in TSS\% at harvesting time might owe much to the higher rate of moisture loss through transpiration. However the reduction in TSS\% during the end of the cold storage period might owe much to the higher rate of sugar loss through respiration than water loss through transpiration (Wills et al., 1998).

The interaction between hybrids and spraying with potassium citrate show that spraying Shanghai hybrid with the two levels of potassium increased significantly TSS\% without significant differences between them, these results are true in both seasons of study. 
Regarding the effect of the interaction between hybrids and cold storage period the results show that the lowest significant TSS\% at the end of cold storage period (21days) was noted by Drasena hybrid, while, the highest values of TSS\% were recorded by Shanghai hybrid at harvesting time. With respect to the interaction between spraying with potassium and cold storage period the same results in Table 8 show that spraying pepper plants with the two levels of potassium recorded the highest significant TSS $\%$ at the beginning of cold storage without significant differences between them, while, the lowest values of TSS\% were recorded from untreated plants at the end of the cold storage period (21days) these results are true in both seasons of study.

Regarding the effect of the interaction among hybrids, spraying with potassium and cold storage period the data in Table 8 indicate that the lowest significant TSS\% at the end of the cold storage period was noted by Drasena hybrid when untreated with potassium which gave 6.20 and $6.13 \%$ in the $1^{\text {st }}$ and $2^{\text {nd }}$ seasons, respectively, on the other hand the highest values of TSS\% were recorded by Shanghai hybrid at the harvesting time when sprayed with potassium citrate at $4 \mathrm{~g} / \ell$ which gave 8.67 and $8.70 \%$ in the $1^{\text {st }}$ and $2^{\text {nd }}$ seasons, respectively, these results are true in both seasons of study.

\section{Fruit firmness:}

Regarding the effect of hybrids on fruit firmness it is obvious from the data in Table 9 that Drasena hybrid recorded the maximum values of fruit firmness as compared to Shanghai hybrid in the two seasons of study but the increment did not reaching to the statistical level.

As to spraying with potassium citrate the results show that spraying pepper plants with the two levels of potassium increased significantly fruit firmness without significant differences between them, while, the lowest values of fruit firmness were recorded from untreated plants. The increased in fruit firmness may be due to that potassium increased the osmotic potential and water uptake and allowed less water loss which has impact on fruit firmness (Epstein 1972). With respect to storage period, it is clear from the results in Table 9 that pepper fruits firmness decreased as the duration of cold storage period is increased the highest values of fruit firmness were recorded at harvesting time, while, the lowest values were recorded at the end of cold storage period (21days) these results are true in both seasons. Similar were reported by Ahmed 2013. The decline in fruit firmness may be due to the gradually breakdown of proto-pectin to lower molecular fractions which are more soluble in water and this directly correlated with the rate of softening of fruits (Wills et al., 1998). Concerning the interaction between hybrids and spraying with potassium the results shoe that spraying both 
hybrids Drasena and Shanghai with potassium citrate at $4 \mathrm{~g} / \ell$ increased significantly fruit firmness followed by spraying both hybrids with potassium citrate at $2 \mathrm{~g} / \ell$ without significant differences among them as compared to control.

The interaction between hybrids and cold storage period show that the highest values of fruit firmness were recorded by both hybrids Drasena and Shanghai at the harvesting time without significant differences between them, while, the lowest significant fruit firmness was noted by both hybrids at the end of storage period (21days). In general the results reveled that there were a significant reduction in fruit firmness of both hybrids by the prolongation of cold storage period in both seasons of study.

With regard to the interaction between spraying with potassium and cold storage period the same results in Table 9 show that spraying pepper plants with potassium citrate at $4 \mathrm{~g} / \ell$ recorded the highest significant of fruit firmness at the harvesting time and after 7 days of cold storage followed by spraying with potassium at $2 \mathrm{~g} / \ell$ at the harvesting time with out significant differences among them in the first season. While, in the second season the maximum values of fruit firmness were recorded by the interaction between spraying with potassium citrate at $4 \mathrm{~g} / \ell$ at the harvesting time followed by potassium citrate at $4 \mathrm{~g} / \ell$ after 7 days of storage without significant differences between them. On the other hand the lowest significant of fruit firmness were obtained at the end of the cold storage period (21days) from untreated plants. These results are true in both seasons of study.

Concerning the effect of the interaction among hybrids, spraying with potassium and cold storage period the data in Table 9 indicate that the highest values of fruit firmness were obtained from both hybrids (Drasena and Shanghai) at the harvesting time when sprayed with potassium at $4 \mathrm{~g} / \ell$. On the other side the lowest significant of fruit firmness were recorded from both hybrids at the end of cold storage period (21days) when untreated with potassium. These results are true in both seasons.

\section{Vitamin C:}

The results in Table 10 show that there were significant differences between the two hybrids in vitamin C content, where hybrid Shanghai gave the maximum values of vitamin C 86.24 and $86.31 \mathrm{mg} / 100 \mathrm{~g}$ fresh weight, hybrid Drasena gave the minimum values of vitamin $C$ content 77.22 and $77.30 \mathrm{mg} / 100 \mathrm{~g}$ fresh weight in the $1^{\text {st }}$ and $2^{\text {nd }}$ seasons, respectively.

Concerning the effect of spraying with potassium the results show that spraying pepper plants with potassium citrate at $4 \mathrm{~g} / \ell$ significantly increased vitamin $\mathrm{C}$ content of sweet pepper fruits. On the other hand the 
lowest values of vitamin $\mathrm{C}$ were found in the fruits obtained from untreated plants. As to cold storage period it is clear from the data that vitamin C content of fruits was significantly increased at the beginning of cold storage and then decreased with the prolongation of the cold storage period in the two seasons. These results are in agreement with those obtained by ElSheikh et al., (1997) and Ahmed (2013) on sweet pepper.

Regarding the effect of the interaction between hybrids and spraying with potassium citrate the results show that spraying Shanghai hybrid with potassium citrate at $4 \mathrm{~g} / \ell$ increased significantly vitamin $\mathrm{C}$ content followed by spraying Shanghai hybrid with potassium citrate at $2 \mathrm{~g} / \ell$ without significant differences between them. With respect to the interaction between hybrids and cold storage period the same data in Table 10 show that the lowest significant vitamin $\mathrm{C}$ content at the end of the cold storage period (21days) was noted by Drasena hybrid, while the highest values of vitamin $\mathrm{C}$ content were recorded by Shanghai hybrid at harvesting time. These results are true in both seasons of study.

Concerning the effect of the interaction between spraying with potassium citrate and cold storage period the results show that spraying pepper plants with the two levels of potassium recorded the highest significant vitamin $\mathrm{C}$ content at the beginning of storage without significant differences between them, while the lowest values of vitamin $\mathrm{C}$ content were recorded by untreated plants at the end of the cold storage period (21days) in the two seasons.

With regard to the interaction among hybrids, spraying with potassium citrate and cold storage period the data in Table 10 indicate that the lowest significant vitamin $\mathrm{C}$ at the end of the cold storage period was noted by Drasena hybrid when untreated plants with potassium which gave 58.33 and $59.49 \mathrm{mg} / 100 \mathrm{~g}$ fresh weight. On the other hand the highest values of vitamin $\mathrm{C}$ content were recorded by Shanghai hybrid at the harvesting time when sprayed with potassium citrate at $4 \mathrm{~g} / \ell$ which gave 95.31 and $96.28 \mathrm{mg} / 100 \mathrm{~g}$ fresh weight in the $1^{\text {st }}$ and $2^{\text {nd }}$ seasons, respectively, in both seasons of study.

Data presented in Table 11 show the results of simple correlation coefficient between sweet pepper yield and its components. The results indicated that total yield per $100 \mathrm{~m}^{2}(\mathrm{~kg})$ showed positive and highly significant correlation with number of fruits per plant, average fruit weight and yield per plant in the two seasons. These results are in a good line with those reported by Mansour et al., (2013). Number of fruits per plant recorded positive and highly significant associations with average fruit weight in both seasons of study. These results are in accordance with those 
Table 11. Some correlation coefficient between yield and its components of some sweet pepper hybrids grown in plastic houses during 2011/2012 and2012/2013 seasons.

\begin{tabular}{|c|c|c|c|c|c|c|c|}
\hline \multirow{2}{*}{\multicolumn{2}{|c|}{ Characters }} & \multicolumn{3}{|c|}{ 2011/2012 Season } & \multicolumn{3}{|c|}{ 2012/2013 Season } \\
\hline & & \multirow{2}{*}{$\frac{1}{0.996^{* *}}$} & \multirow{2}{*}{$\begin{array}{c}2 \\
0.978^{* * *}\end{array}$} & \multirow{2}{*}{$\frac{3}{1.000 *}$} & \multirow{2}{*}{$\begin{array}{c}1 \\
0.995^{* *}\end{array}$} & \multirow{2}{*}{$\frac{2}{0.967^{* *}}$} & \multirow{2}{*}{$\frac{3}{1.000 * * *}$} \\
\hline $\mathbf{Y}$ & Total yield $\left(\mathrm{kg} / \mathbf{1 0 0 m ^ { 2 }}\right)$ & & & & & & \\
\hline 1 & No. of fruit/plant & & $0.954^{* *}$ & $0.996^{* * *}$ & & $0.936 * *$ & $0.995 * *$ \\
\hline 2 & Average fruit weight (g) & & & $0.978^{* * *}$ & & & $0.967^{* *}$ \\
\hline 3 & yield / plant (kg) & & & & & & \\
\hline
\end{tabular}

found by Mansour et al., (2013). Again average fruit weight showed highly and positively significant correlation with yield per plant in the two seasons.

Conclusively, from the previous results of this investigation, it could be concluded that spraying sweet pepper Shanghai hybrid with potassium citrate at $4 \mathrm{~g} / \ell$ was sufficient to produce the highest yield and its components, and improved quality and storability of fruits.

\section{REFERENCES}

Abbott, J. A. (1999). Quality measurements of fruits and vegetable postharvest. Biol. Technol., 15:207-225.

Ahmed, N. A. G., (2013). Effect of some pre and postharvest treatments on yield, quality and storability of sweet pepper. M.Sc. Thesis, Fac. of Agric., Cairo Univ. Egypt.

Antoniali, S., PA. Martins Leal, AM. de Magalaes, RT Fuziki and J. Sanches (2007). Physico-chemical characterization of 'Zarco HS' yellow bell pepper for different ripeness stages. Scientia Agricola (Piracicaba, Brazil), 64 (1): 19-22.

A.O.A.C. (1990). Quality of Official Analytical Chemists $15^{\text {th }}$ Ed. Washington DC. USA.

Arancon, N.Q., C.A. Edwards, S. Lee and R. Byrne (2006). Effects of humic acids from vermicomposts on plant growth. European J. Soil Bio., 42 (Suppl.1): S65-S69.

Cakmak, I., (2005). The role of potassium in alleviating detrimental effects of abiotic stresses in plants. J. Plant Nutr. Soil Sci., 168: 521-530. 
El-Bassiony, A.M., Z.F. Fawzy, E.H. Abd El-Samad and G.S. Riad (2010). Growth, Yield and Fruit Quality of Sweet Pepper Plants (Capsicum annuum L.) as Affected by Potassium Fertilization. $J$. of American Sci., 6(12):722-729.

El-Sheikh, T. M., S. Z. Abd El-Rahman and S. M. Hassanen (1997). Effect of calcium chloride and hydrated lime on keeping quality of sweet pepper and cucumber fruits. Annals Of Agric. Sci., Moshtohor, 35 (4):2371-2389.

El-Tohamy, W.A., A.A. Ghoname and S.D. Abou-Hussein (2006). Improvement of pepper growth and productivity in sandy soil by different fertilization treatments under protected cultivation, $J$. of Appl. Sci. Res., 21(1): 8-12.

Epstein, E. (1972). Mineral nutrition of plants principles and perspectives. Joh, Willy and Sons, Inc., New York.

Darwesh, F. M. A., and A. S. H. Atress (2011). Effect of spraying with potassium and magnesium on yield, quality and storability of snow pea (Pisum sativum var macrocarpon), J. of Appl. Sci. Res., 26 (12): 312-327.

Hasler, CM. (1998). Functional foods: their role in disease prevention and health. Food Technol., 52:63-69.

Hassan, G.H.H. (2002). Effect of spraying sugar peas plants with potassium fertilizer on yield and pods storability. M.Sc. Thesis, Fac. of Agric., Alexandria Univ. Egypt.

Howard, LR., ST. Talcott, CH. Brenes and B. Villalon (2000). Changes in phytochemical and antioxidant activity of selected pepper hybrids (Capsicum species) as influenced by maturity. J. Agric. Food Chem., 48:1713-1720.

Hsiao, C. and A. Läuchli, (1986). Role of potassium in plant-water relation. In: Advances in plant nutrition 2, pp: 281-312. Tinker and A. Läuchli(eds.). Praeger, New York.

Imas, P. and S.K. Bansal, (1999). Potassium and integrated nutrient management in potato. Presented at the global conference on potato, December., 6-11, New Delhi, India.

Lester, G. E., J. L. Jifon and D. J. Makus (2010). Impact of potassium nutrition and food quality of fruits and vegetables. A condensed and concise review of literature. Better Crops with Plant Foods; 94(1): 1821 many ref.

Mansour, N. T. S., E. E. A. Abbas and A. I. Amer (2013). Efficiency of foliar spraying with some natural plant extracts on growth, dry seed yield and rust disease incidence of cowpea (Vigna unguiculata L.). J. of Appl. Sci. Res., 28(5): 201-217. 
Marschner, H., (1995a). Mineral nutrition of higher plants. Academic press, London, 4th printing., pp: 889.

Marschner, H., (1995b). Mineral nutrition of higher plants (Academic Press, San Diego, CA), 2nd Ed, pp: 299-312.

Munij. J. O. and Almedia, J. I. L., De, 1998. Performance of capsicum hybrids, Horticultura Brasileira, 6 (1): 18-19.

Nassar, H.H., M.A. Barakat, T.A. El-Masry and A.S. Osman (2001). Effect of potassium fertilization and paclobutrazol foliar application on vegetative growth and chemical composition of sweet pepper. Egypt. J. of Hort., 28 (1):113-129.

Rahman, A. S. Z. and El-Sheikh, T. M., (1994). A comparative study of some sweet pepper cultivation grown under plastic house conditions for yield and stability. Egyptian J. Hortic., 21 (2): 213-215.

Sakaldas, M. and K. Kaynas (2010). Biochemical and quality parameters changes of green sweet bell pepper as affected by different postharvest treatments. Afr. J. Biotech., 9 (48):8174-8181.

Shibairo, S. I., M. K. Upadhyaya and P. M. A. Toivonen (1998). Potassium nutrition and post harvest moisture loss in carrots (Daucus carota L.). J. Hort. Sci. \& Biotec., 73 (6): 862-866.

Snedecor, G. W. and W. G.Cochran (1980). Statistical Methods. $7^{\text {th }}$ Ed. The Iowa State Univ., Press, Amer., Iowa, USA.

Vicente, A. R., C. Pineda, L. Lemoine, P. M. Civello, G. A. Martinez and A. R. Chaves (2005). UV-C treatments reduce decay, retain and alleviate chilling injury in pepper. Postharvest Biol. Technol., 35:69-78.

Wills, R., B. Mcglasson, D. Graham and D. Joyce (1998). Post-harvest: An introduction to the physiology and handling of fruit, vegetables and ornamentals. Ed.: CAB International, Wallingford, UK. 


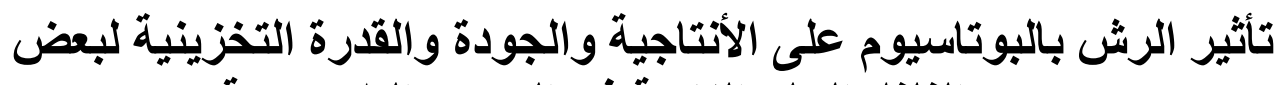
هجن القلقل الحلو النامية فى الصوبة والجودة البلاستيكية

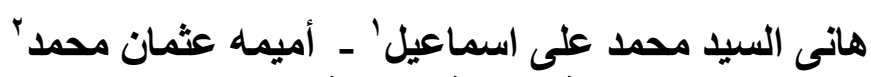

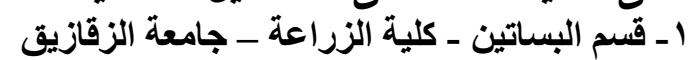

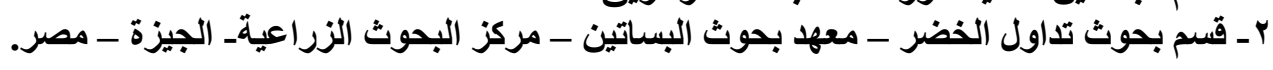

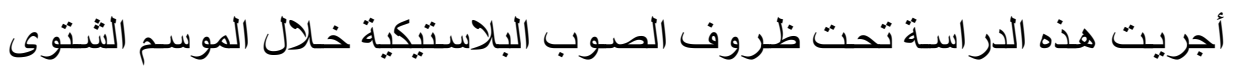

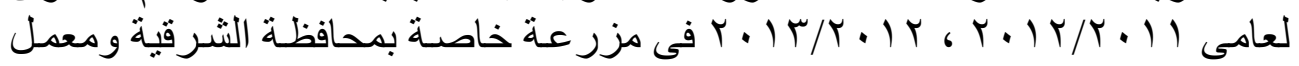

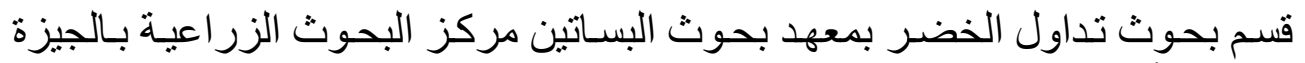

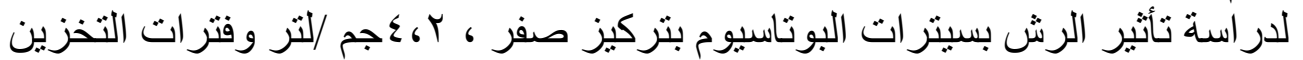

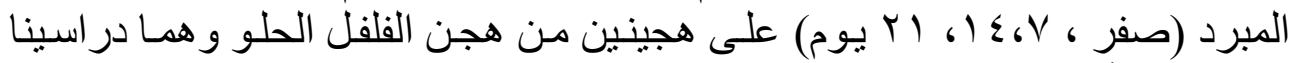

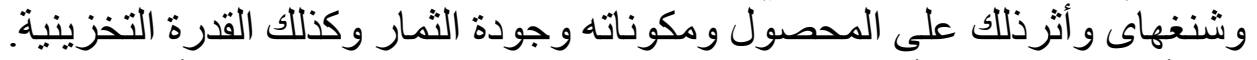

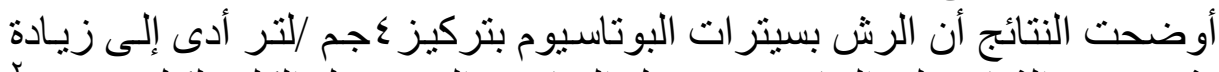

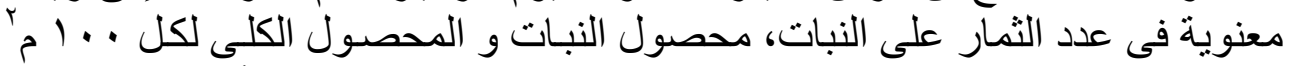

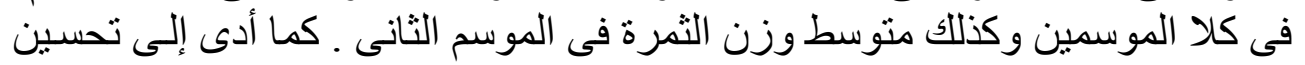

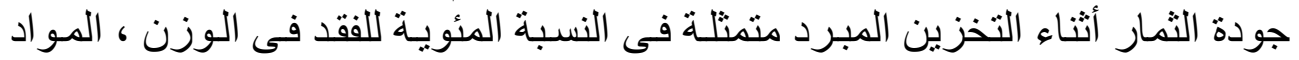

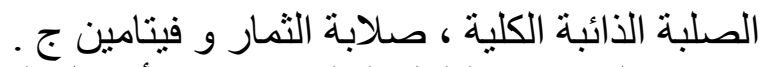

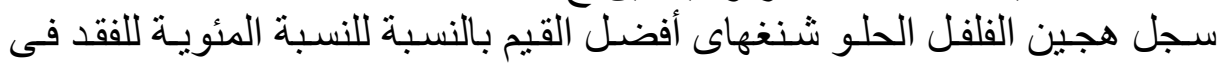

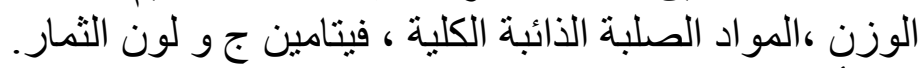

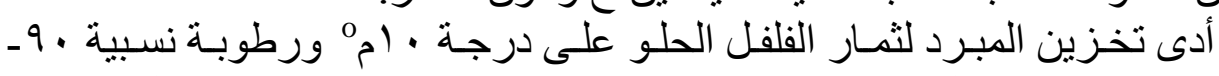

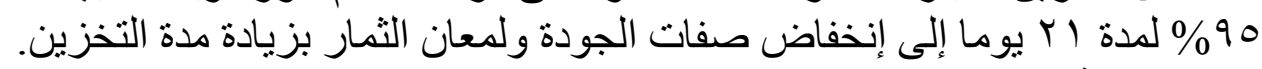

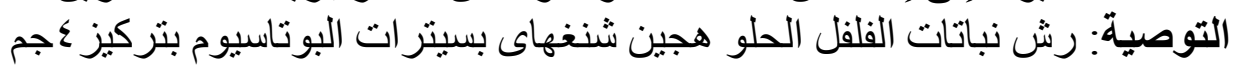

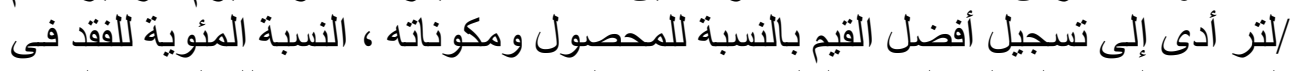

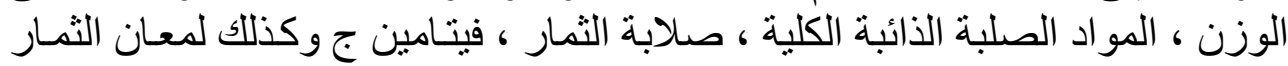

